\title{
An Aerial Radiological Survey of Selected Areas of Area 18 - Nevada Test Site
}

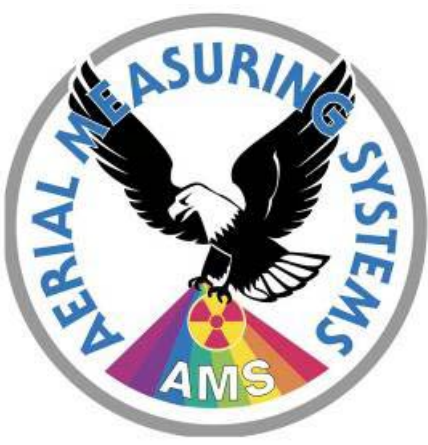

Craig Lyons

Project Scientist

Remote Sensing Laboratory-Nellis

Survey Date:

December 11, 2008

This document is UNCLASSIFIED

Reviewed by

Timothy Rearich

Derivative Classifier

This work was done by National Security Technologies, LLC, under Contract No. DE-AC52-06NA25946 with the U.S. Department of Energy. 


\section{DISCLAIMER}

This report was prepared as an account of work sponsored by an agency of the U.S. Government. Neither the U.S. Government nor any agency thereof, nor any of their employees, nor any of their contractors, subcontractors or their employees, makes any warranty or representation, express or implied, or assumes any legal liability or responsibility for the accuracy, completeness, or usefulness of any information, apparatus, product, or process disclosed, or represents that its use would not infringe privately owned rights. Reference herein to any specific commercial product, process, or service by trade name, trademark, manufacturer, or otherwise, does not necessarily constitute or imply its endorsement, recommendation, or favoring by the U.S. Government or any agency thereof. The views and opinions of authors expressed herein do not necessarily state or reflect those of the U.S. Government or any agency thereof. 


\section{Table of Contents}

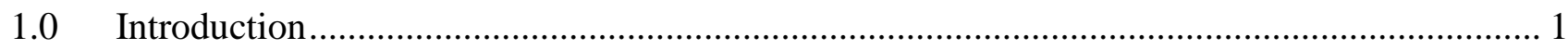

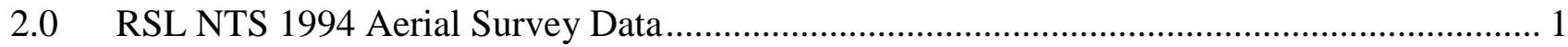

3.0 Gross-Count Map (2008 Survey)......................................................................................... 2

4.0 Man-Made Net-Count Results (2008 Survey) ……………................................................ 2

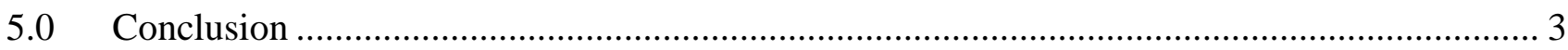

6.0 AMS Survey Personnel and Parameters …………............................................................... 13

\section{Figures}

Figure 1. Helicopter flight lines over NTS Area 18 (Johnnie Boy and Little Feller I) ..................... 4

Figure 2. NTS Area 181994 Aerial Survey Results for Am-241 ……………………................. 5

Figure 3. NTS Area 181994 Aerial Survey Results for Man-made Exposure Rate.......................... 6

Figure 4. NTS Area 18 Gross Count Results (Johnnie Boy and Little Feller I) ............................... 7

Figure 5. NTS Area 18 Man-Made Net Count Results (Johnnie Boy and Little Feller I) ................. 8

Figure 6. NTS Area 18 Cs-137 Net Count Results (Johnnie Boy and Little Feller I) ...................... 9

Figure 7. NTS Area 18 Co-60 and Eu-152 Net Count Results (Johnnie Boy and Little Feller I) .. 10

Figure 8. NTS Area 18 Am-241 Net Count Results (Johnnie Boy and Little Feller I).................... 11

Figure 9. NTS Area 18 U-235 Net Count Results (Johnnie Boy and Little Feller I)....................... 12 


\subsection{Introduction}

As part of the proficiency training for the Radiological Mapping mission of the Aerial Measuring System (AMS), a survey team from the Remote Sensing Laboratory-Nellis (RSL-Nellis) conducted an aerial radiological survey of selected areas of Area 18 of the Nevada Test Site (NTS) for the purpose of mapping man-made radiation deposited as a result of the Johnnie Boy and Little Feller I tests. The survey area centered over the Johnnie Boy ground zero but also included the ground zero and deposition area of the Little Feller I test, approximately 7,000 feet (2133 meters) southeast of the Johnnie Boy site.

The survey was conducted in one flight. The completed survey covered a total of 4.0 square miles. The flight lines (with the turns) over the surveyed areas are presented in Figure 1. One 2.5-hour-long flight was performed at an altitude of $100 \mathrm{ft}$ above ground level (AGL) with 200 foot flight-line spacing. A test-line flight was conducted near the Desert Rock Airstrip to ensure quality control of the data. The test line is not shown in Figure 1. However, Figure 1 does include the flight lines for a 'perimeter" flight. The path traced by the helicopter flying over distinct roads within the survey area can be used to overlay the survey data on a base map or image. The flight survey lines were flown in an east-west orientation perpendicular to the deposition patterns for both sites. This technique provides better spatial resolution when contouring the data.

The data were collected by the AMS data acquisition system (REDAR V) using an array of twelve 2" $\times 4 " \times 16 "$ sodium iodide $(\mathrm{NaI})$ detectors flown on-board a twin-engine Bell 412 helicopter. Data, in the form of gamma energy spectra, were collected every second over the course of the survey and were geo-referenced using a differential Global Positioning System. Spectral data allows the system to distinguish between ordinary fluctuations in natural background radiation levels and the signature produced by man-made radioisotopes. Spectral data can also identify specific radioactive isotopes.

Based on the results of the RSL NTS 1994 surveys, this area was chosen for a resurvey to improve the spatial resolution of the reported depositions for the Johnnie Boy and Little Feller I events. In addition, the survey was expected to confirm the absence of detectable concentrations of Americium241 (Am-241) at the Johnnie Boy site and attempt to confirm the presence of Uranium-235 (U-235).

\subsection{RSL NTS 1994 Aerial Survey Data}

During August and September 1994, RSL conducted an aerial radiological survey of the NTS. The purpose of the survey was to provide a more detailed measurement of the NTS gamma radiation natural background and areas of man-made activity identified in a 1992 aerial survey. The survey utilized Messerschmitt-Bölkow-Blohm (MBB) BO-105 helicopters at an altitude of 60 meters (200 feet) with a 150 meter (500 foot) line spacing. The survey lines were flown in a north-south direction with an average flight-line length of 80 kilometers (50 miles). The 1994 survey system utilized eight $2 " \times 4 " \times 16$ " NaI detectors. Examples of the two primary 1994 survey data products are shown in Figures 2 and 3 . 


\subsection{Gross-Count Map (2008 Survey)}

The exposure-rate map is derived from the gross-count data that represent total counts per second detected in the twelve $2 " \times 4 " \times 16 " \mathrm{NaI}$ detectors. The gross count integrates total count rates of the spectra between 38 and 3,026 keV. The gross counts include all natural background and man-made radioisotopes. Terrestrial and cosmic radiations are the largest contributors to the natural background. In general, terrestrial background will vary with geological formation and changes in the ground coverage around the area. For this survey over a portion of Area 18, the variation in the gross count depicted in Figure 4 is evidence of the presence of man-made radioisotopes as previously documented from the 1994 NTS aerial survey results in addition to the natural background contributions.

\subsection{Man-Made Net-Count Results (2008 Survey)}

The man-made gross-count map is the fraction of the gross counts that are directly attributable to gamma radiation from man-made radioisotopes. The man-made gross count can be determined by subtracting natural background contributions (terrestrial and cosmic gamma radiation) from the gross count. The algorithm identifies regions in the survey area where the shape of the energy spectrum deviates significantly from the shape of the background or reference spectrum. These deviations in the shape of the spectrum are driven by the characteristics of longer half-life man-made isotopes generally limited to gamma-ray energy ranges below $1400 \mathrm{keV}$ while naturally occurring isotopes occur throughout the measured energy range $(0-4,000 \mathrm{keV})$. Changes in the ratio of the low-energy to high-energy count rates indicate the presence of man-made isotopes within the survey area. The counts collected for the low-energy (man-made isotopes) include those for the key gammas for specific isotopes and all the Compton-scattered gamma rays.

Figure 5 shows the man-made gross-count maps of the survey area. The obtained results agree with the previous 1994 survey results and indicate the presence of man-made radioactivity over the survey area.

The man-made net count results provide guidance for combining the one-second spectra results of any flight line indicating the presence of man-made isotopes. The combined spectra can then be used to define region-of-interest (ROI) extractions for specific isotopes.

\subsection{Cesium-137 (Cs-137) Net Count Results (2008 Survey)}

Figure 6 shows the results of this process for Cs- 137.

4.2 Cobalt-60 (Co-60) and Europium-152 (Eu-152) Net Count Results (2008 Survey)

Figure 7 shows the results of this process for Co-60 and Eu-152.

\subsection{Americium-241 (Am-241) Net Count Results (2008 Survey)}

Figure 8 shows the results of this process for Am-241. 


\subsection{Uranium-235 (U-235) Net Count Results (2008 Survey)}

Figure 9 shows the results of this process for $\mathrm{U}-235$. When the spectral extraction analysis for a specific nuclide produces no results statistically above a 3-sigma threshold, the data results are presented as count rate levels, both negative and positive, around the count rate range for the key gamma ROI. The number of negative and positive results shown on the map should be equivalent.

These extractions are an estimate of the number of measured counts that are attributable to specific radioisotopes.

\subsection{Conclusion}

The December 2008 survey was conducted at a lower altitude and closer line spacing than the 1994 survey. These flight parameters provided superior spatial resolution and sensitivity required for measuring the radioisotopes associated with the Johnnie Boy and Little Feller I events. Results for the man-made net count rate and Am-241 depositions were very similar in extent and position between the 1994 and 2008 survey results. The most notable feature for the Johnnie Boy deposition is the absence of a detectable Am-241 footprint. The presence of Am-241 in a deposition footprint for a low-yield fission event or safety shot event would confirm the presence of various isotopes of weapons-grade plutonium. The relatively small deposition footprint for Johnnie Boy containing Cs137 and Co-60 as fission products and Eu-152 as a soil activation product confirms that the device produced a nuclear yield. However, the negligible Am-241 levels indicate that it was not a plutoniumbased device. Aerial survey results for U-235 which could indicate it was a HEU- based device are inconclusive. Confirmation of the presence of U-235 inside the deposition footprint requires the use of ground based spectral systems.

In addition to the ground-truth effort for determining the presence of U-235, in-situ measurements using a pressurized-ion-chamber (PIC) should be conducted at the Johnnie Boy site to validate exposure rate conversion factors from the man-made net count data to a 1 meter exposure rate map product. The 1994 survey data was converted to nominal 1-meter exposure rates as one of the primary products. The exposure rate maps have been used to plan for current and future land uses at a number of the NTS ground zero locations. Subsequent surveys conducted by RSL need to produce similar 1-meter exposure rate map products that can be evaluated against the previous 1994 results. 


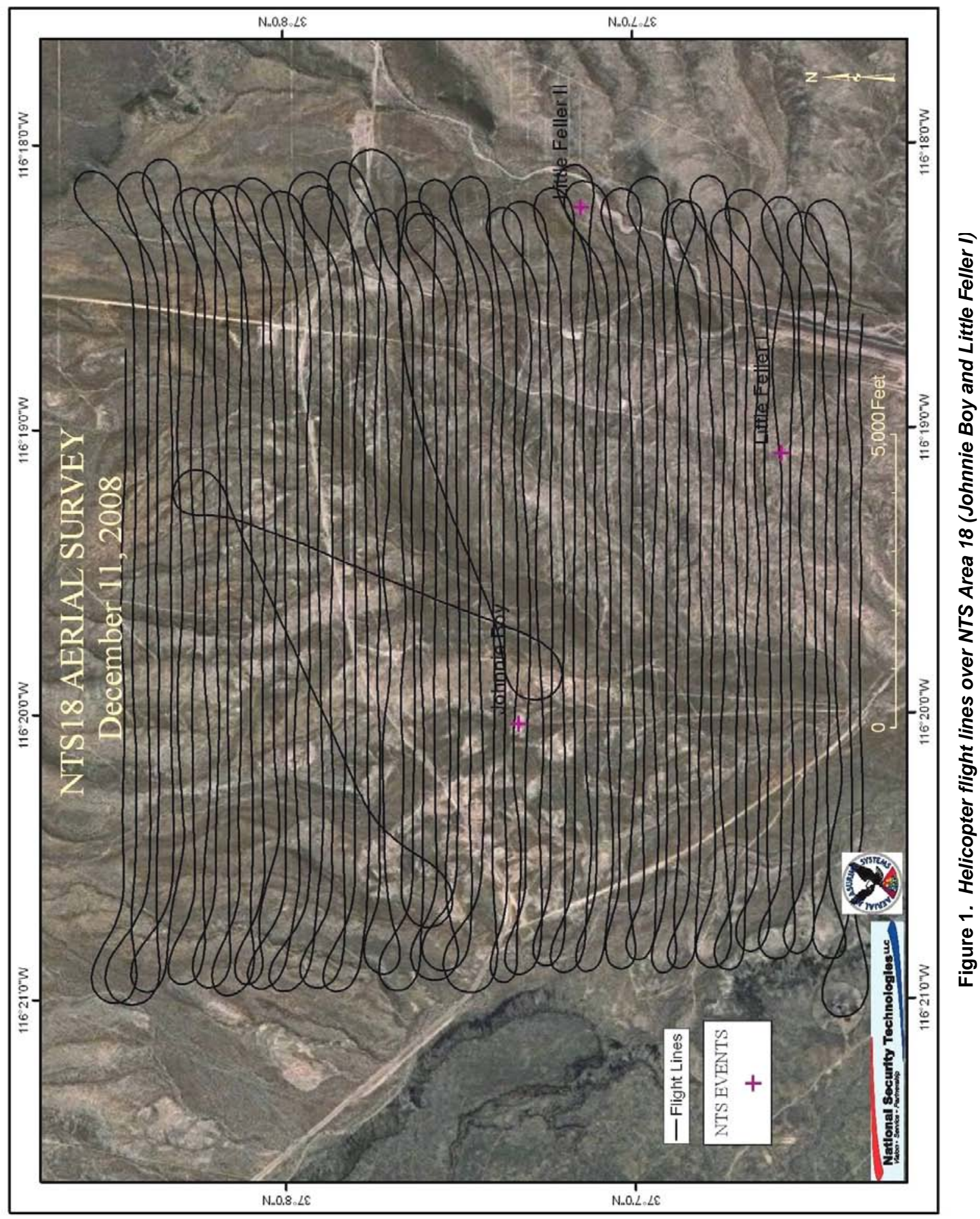




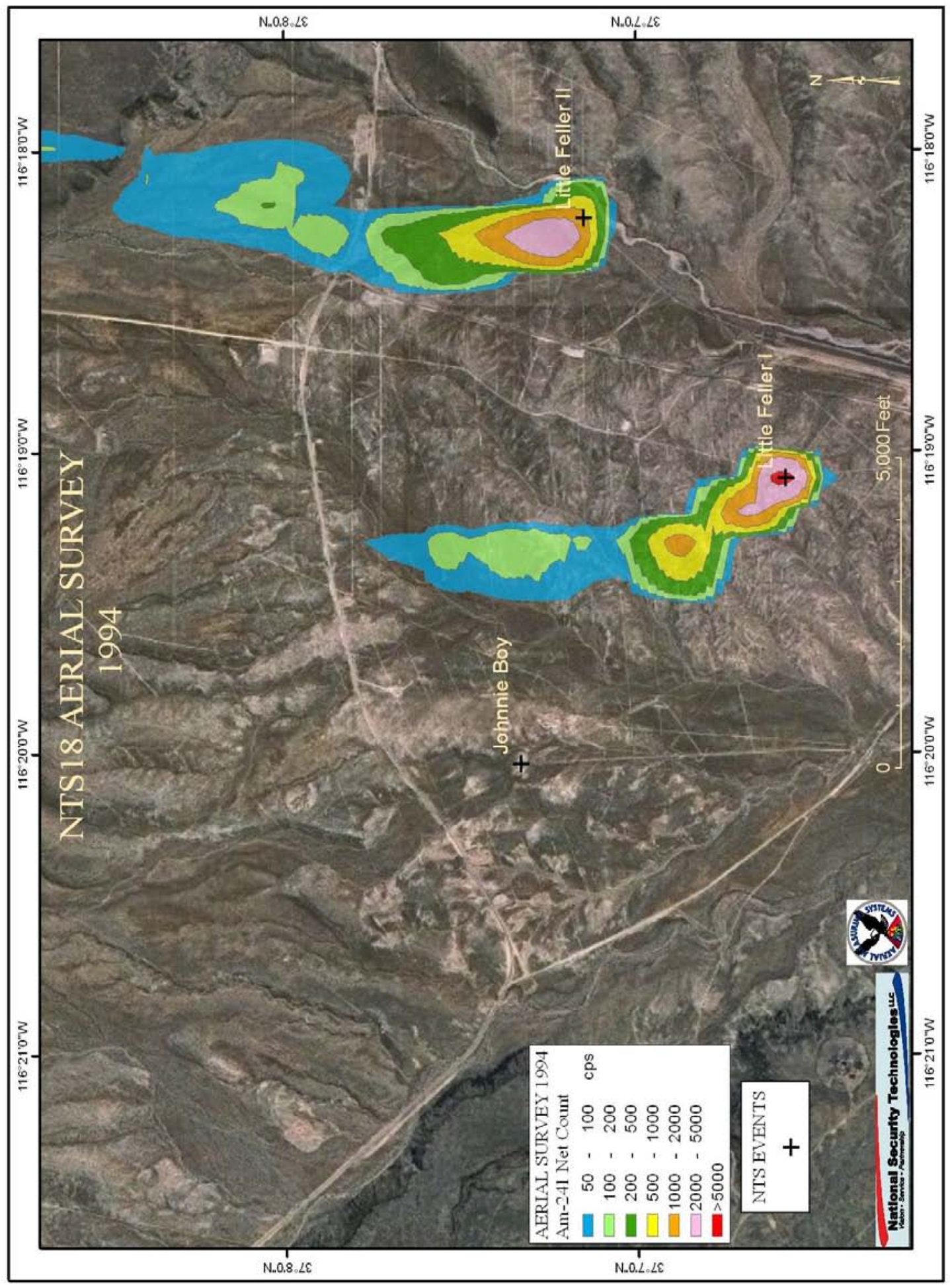

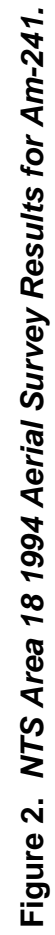




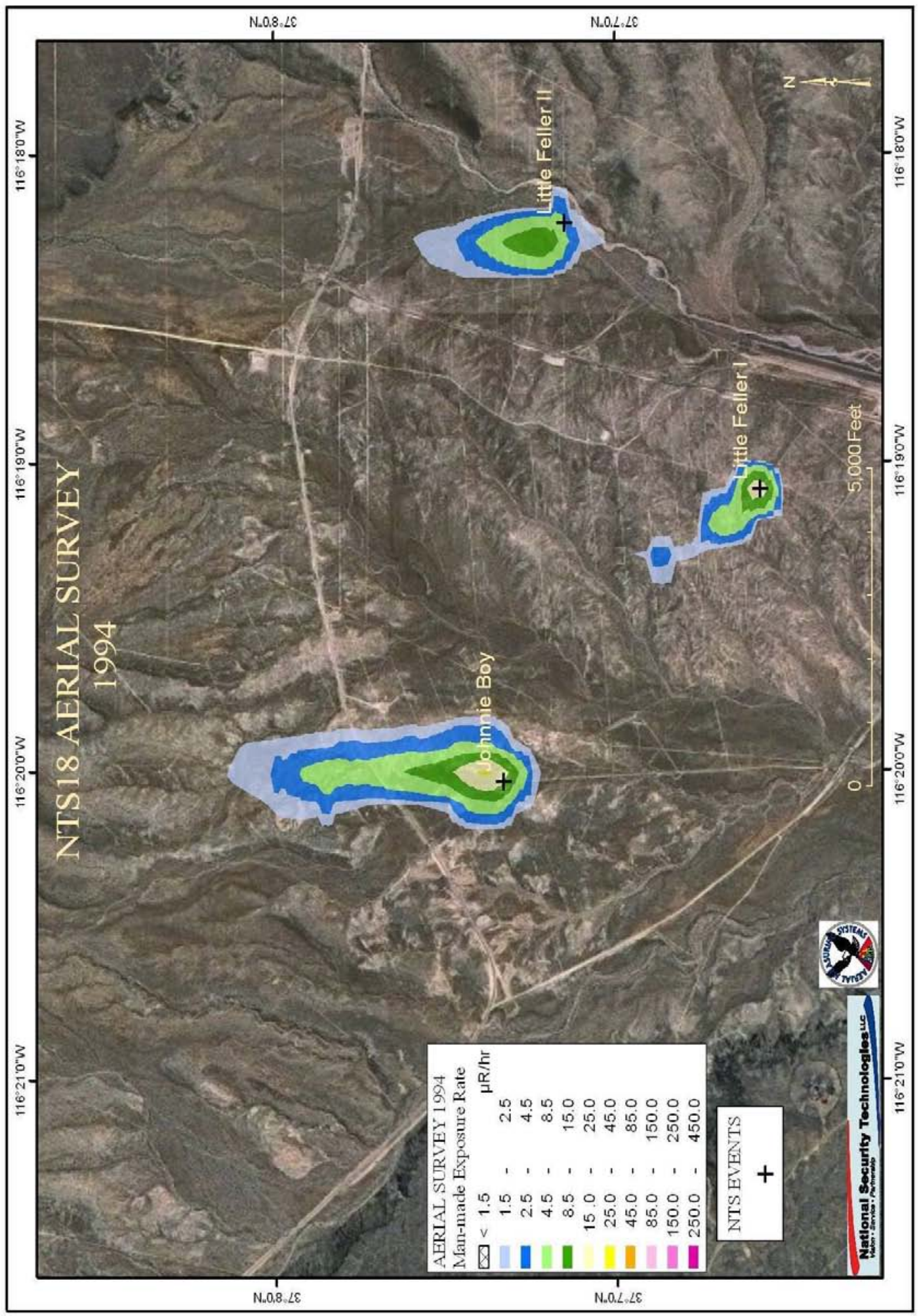

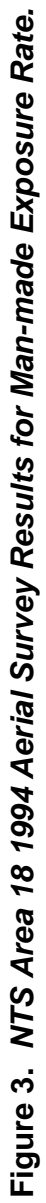




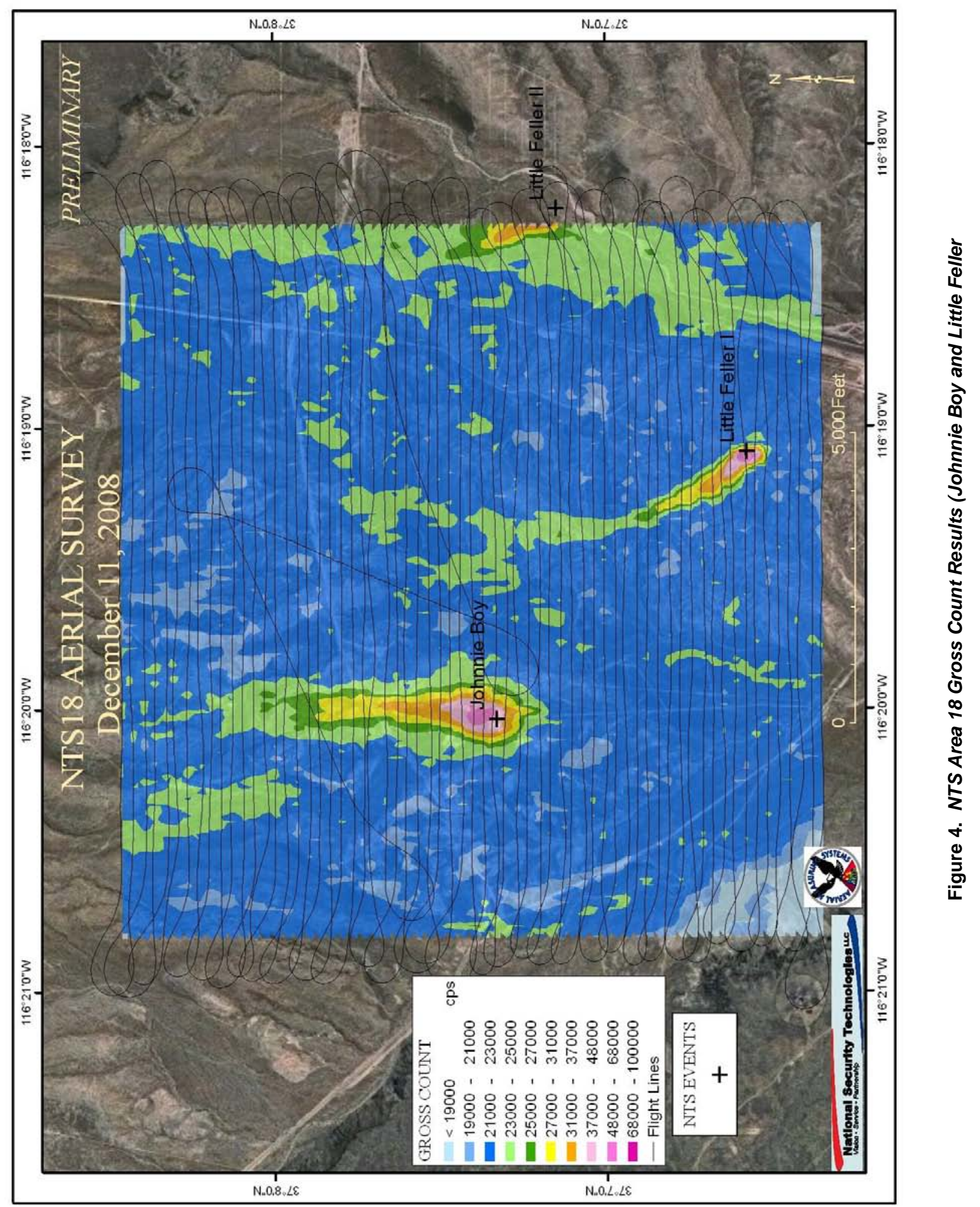




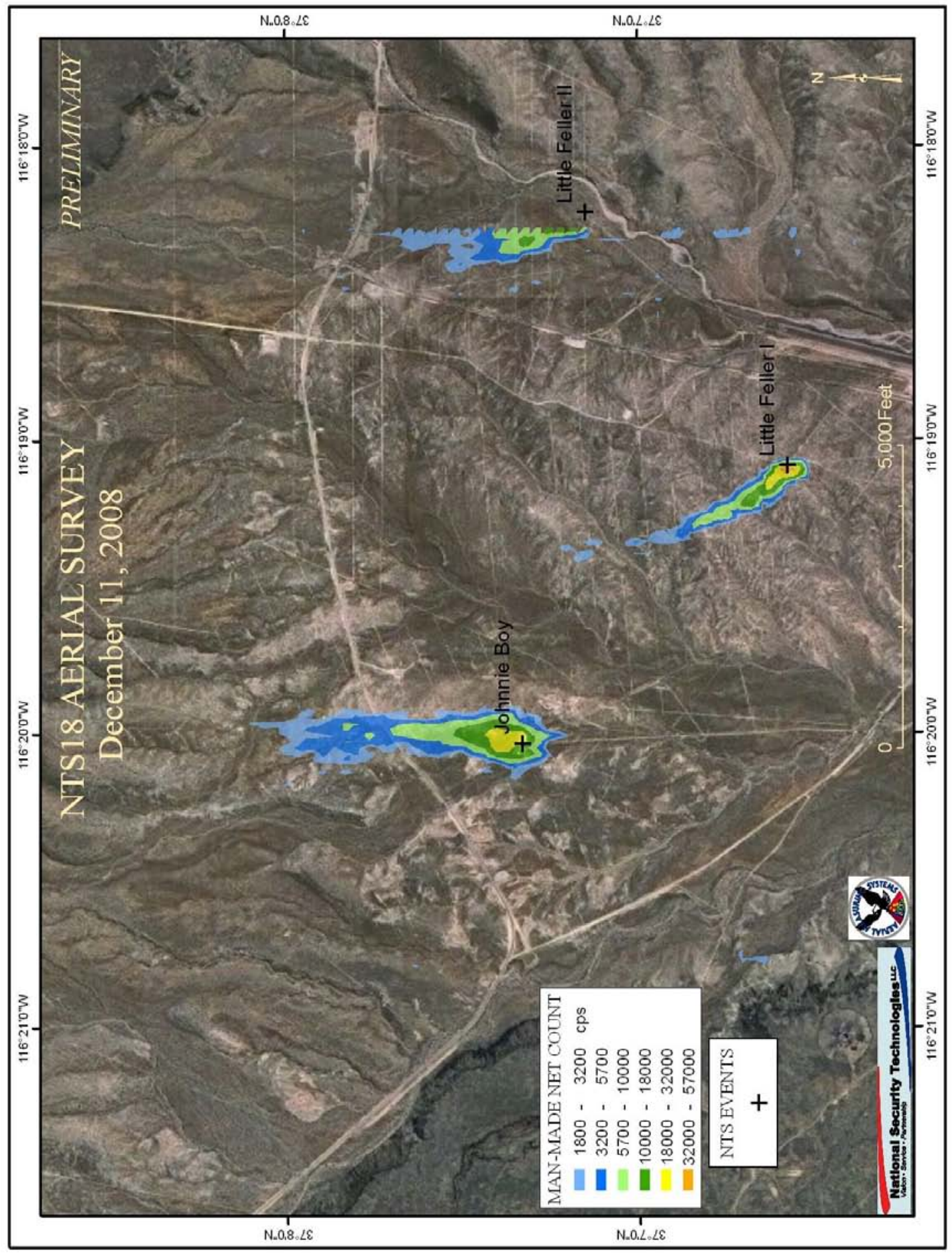

|0 


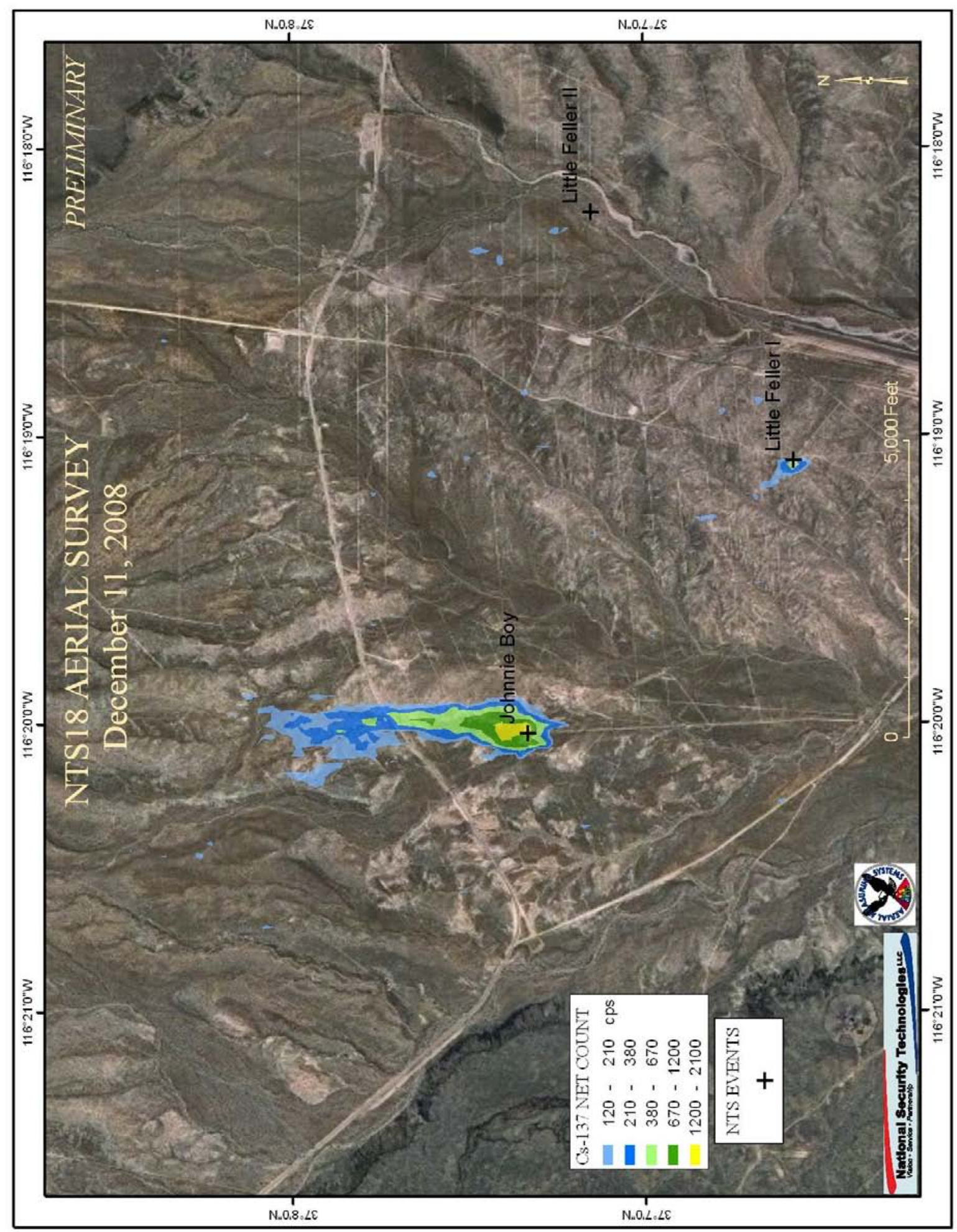

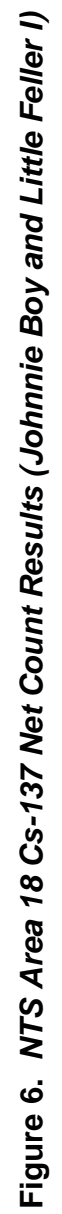




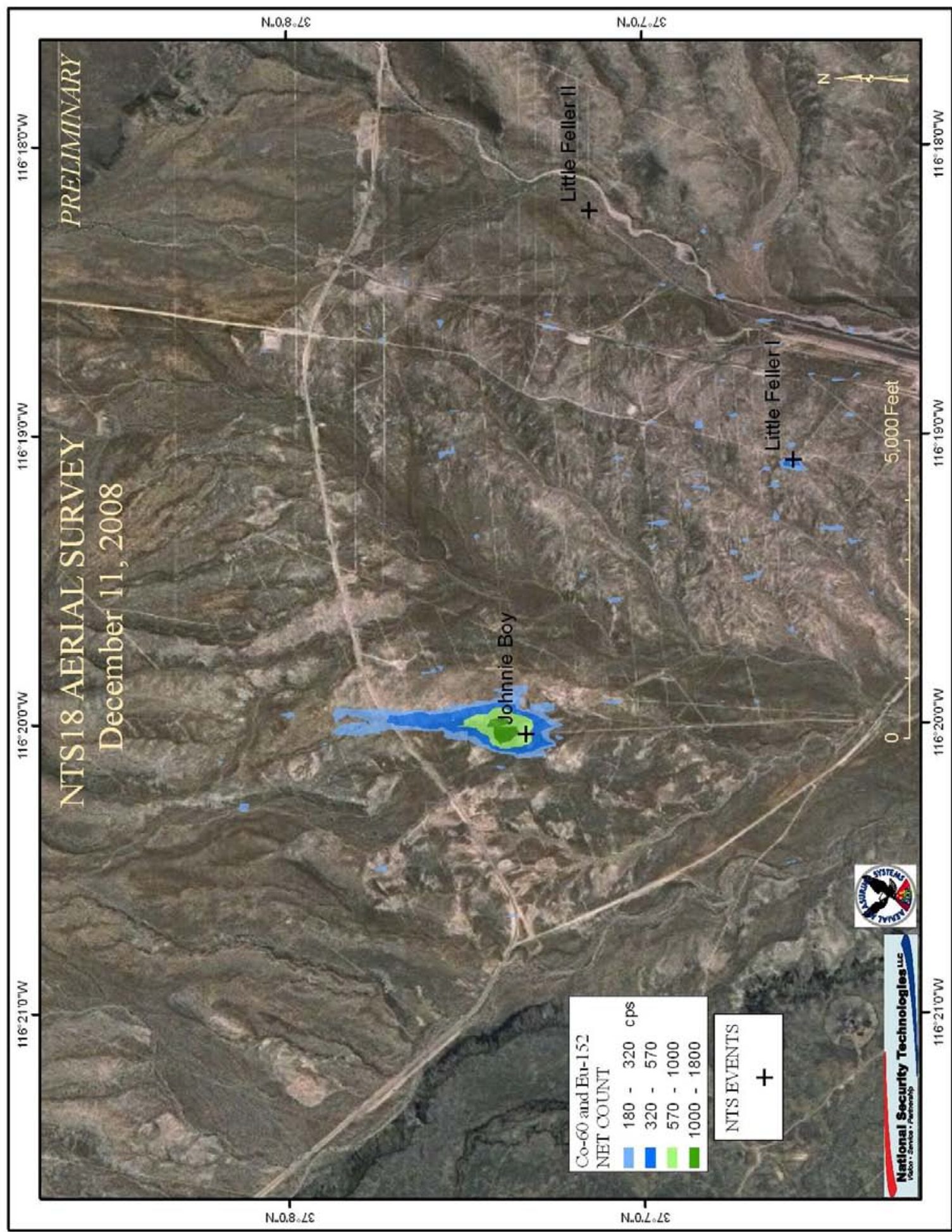

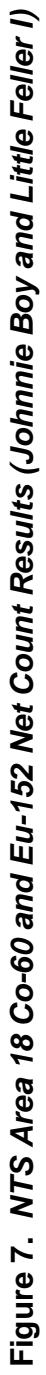




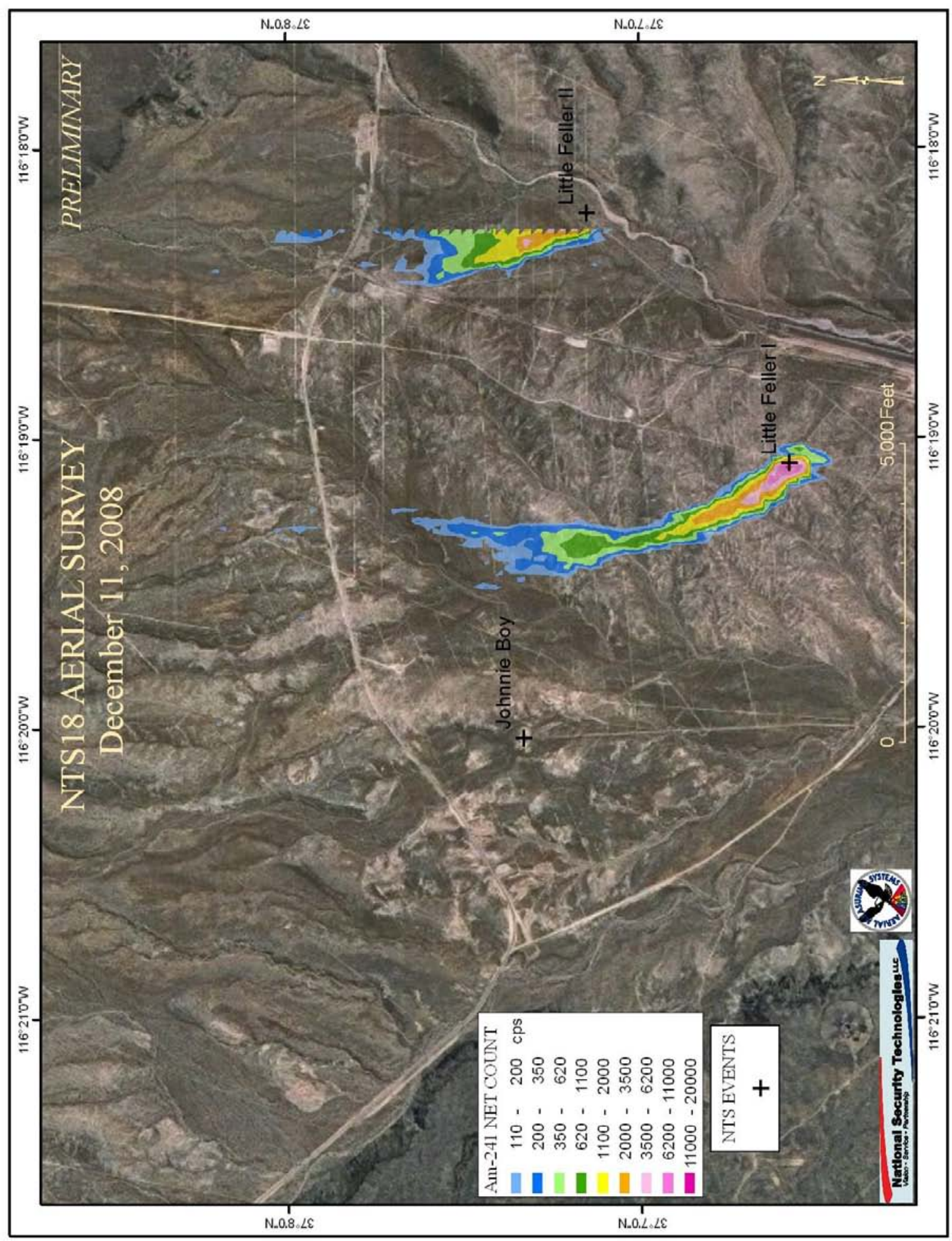

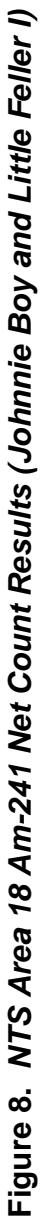




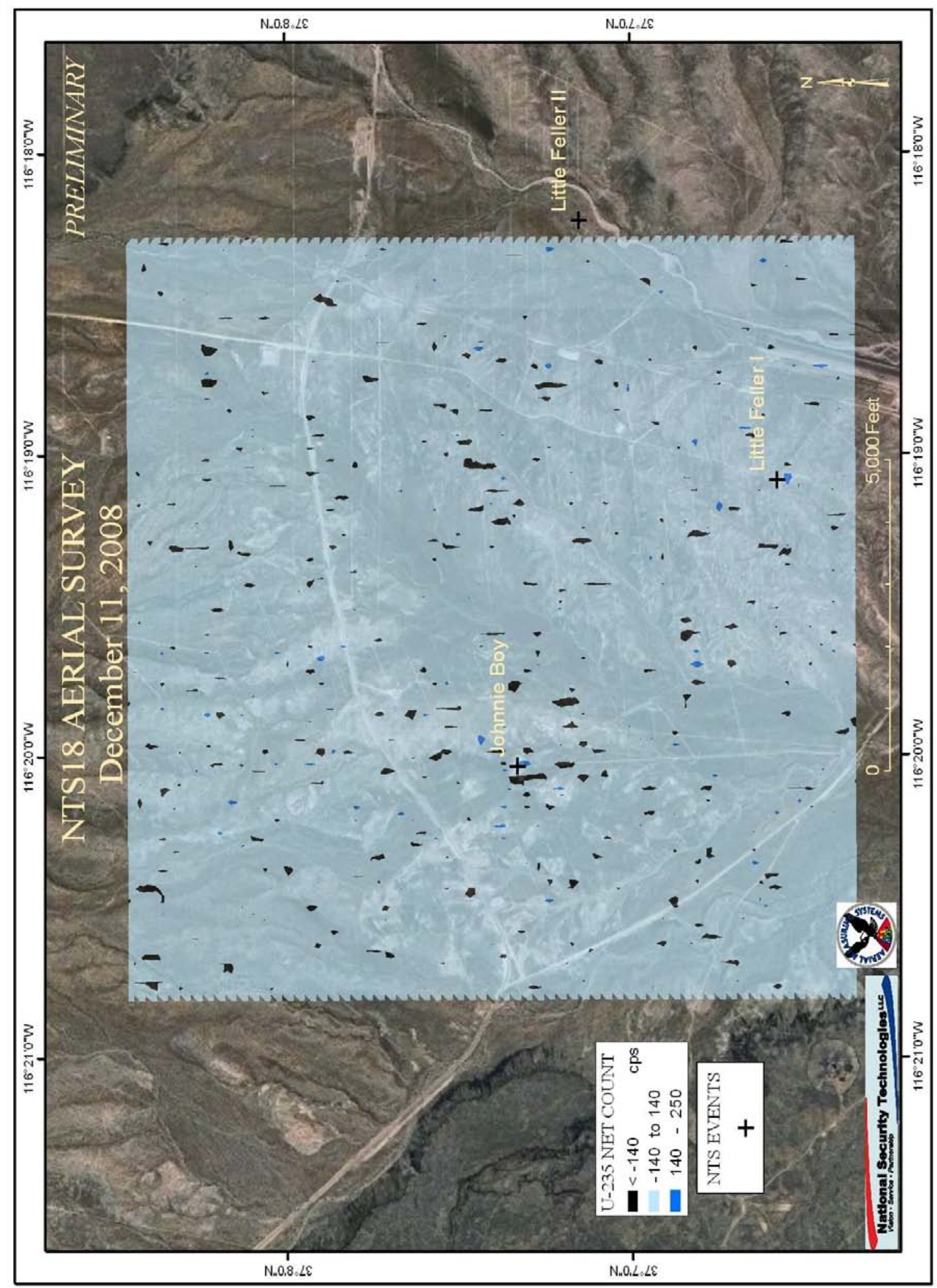

ป 


\subsection{AMS Survey Personnel and Parameters}

\begin{tabular}{|ll|}
\hline \multicolumn{2}{|c|}{ AMS Mission Personnel } \\
\hline Name & Position \\
\hline Joe Ginanni & Federal Team Lead \\
\hline Craig Lyons & AMS Mission Manager \\
\hline Thane Hendricks & AMS Data Scientist \\
\hline Joseph Ginanni & Federal AMS Manager \\
\hline Karen McCall & AMS Manager \\
\hline Tom McKissack & Pilot \\
\hline Tom Selfridge & Pilot \\
\hline Tuyet Nguyen & Data Analyst \\
\hline Bert Cochran & Electronic Technician \\
\hline Mike Lukens & Electronic Technician \\
\hline Joe Cummings & Mechanic \\
\hline
\end{tabular}

\begin{tabular}{|c|c|}
\hline \multicolumn{2}{|c|}{ Survey Parameters } \\
\hline Name of Location & Johnnie Boy - NTS Area 18 \\
\hline Length & 1.65 Miles \\
\hline Width & 2.42 Miles \\
\hline Type of Survey & Proficiency \\
\hline Number of Areas & One \\
\hline Coverage & 4.00 square miles \\
\hline Altitude & 100 feet \\
\hline Speed & 70 knots \\
\hline Line Spacing & 200 feet \\
\hline Average Line Length & 1.9 Miles \\
\hline \multicolumn{2}{|c|}{ Steering } \\
\hline Base latitude (degrees) & 37.129994 \\
\hline Base longitude (degrees) & -116.329172 \\
\hline Angle (degrees) & 0 \\
\hline
\end{tabular}

